\title{
SANTIAGO RONCAGLIOLO: LA CUARTA ESPADA Y LA COMERCIALIZACIÓN DE LA IZQUIERDA MILITANTE
}

Lucas Izquierdo

University of Central Florida

https://doi.org/10.18778/8220-195-6.28

\section{Resumen}

Santiago Roncagliolo comercializa la izquierda militante peruana en La cuarta espada: La historia de Abimael Guzmán y Sendero Luminoso (2007). Catalogada como una versión periférica de Truman Capote In Cold Blood (1966), la novela investiga un levantamiento guerrillero que culminó con la muerte de sesenta mil civiles. El artículo argumenta que Roncagliolo combina las propuestas teóricas de Mariátegui, fundador del partido socialista peruano, con la labor de las comisiones de derechos humanos latinoamericanos para concebir una novela de consumo masivo.

Palabras clave: Perú, Sendero Luminoso, violencia, literatura.

El periodista Santiago Roncagliolo explora la intersección de estética y política en su novela La cuarta espada: La historia de Abimael Guzmán y Sendero Luminoso (2007). Catalogada como una versión peruana de Truman Capote In Cold Blood (1966), la novela encarna la experiencia de una revolución guerrillera. El narrador reflexiona sobre la construcción meta-literaria de una realidad histórica mientras va desenmascarando al líder guerrillero Abimael Guzmán (1934-). El acercamiento simula una investigación detectivesca de un desgarrador episodio histórico que concluyó con la muerte de sesenta y nueve mil civiles. Los muertos, en su 
mayoría Quechua hablantes del interior peruano, fueron ultimados en fuego cruzado entre las fuerzas armadas y los militantes de izquierda. El artículo argumenta que las estrategias holográficas que forjan esta novela de consumo masivo combinan las propuestas teóricas de José Carlos Mariátegui (1894-1930), fundador del partido socialista peruano, con la labor de las comisiones de derechos humanos.

En La cuarta espada, el posicionamiento del narrador re-postula una realidad virtual para el consumidor globalizado. Las fuerzas del mercado enmarcan la racionalidad del momento. Es una correspondencia que recicla el enfrentamiento de centro y periferia, el cual es mediado en el texto con el intercambio de derechos inalienables. La parodia, acentuada por el narrador suministrando un producto cultural, radica en justificar el valor de un relato que involucró la muerte de decenas de miles de personas. Múltiples escenarios generan una cartografía mental, emocional y física del proceso histórico. Estas incluyen dimensiones meta-literarias que incorporan el posicionamiento editorial del texto. El marketing que propone el narrador para vender la historia, sobre el cual se monetiza el producto cultural, se funda en un crimen que abarca a todos los sectores de la sociedad peruana. El proceso histórico, inducido por una sublevación guerrillera, involucra asumir una responsabilidad compartida que reflexione sobre las razones estructurales que permitieron la gestación de la insurrección, incluyendo la ausencia de reconocimiento de las comunidades andinas, los agentes de la violencia y la geopolítica de la guerra fría.

El encuentro de arte y sociedad conlleva un distanciamiento reflexivo que incorpora la producción, distribución y recepción del texto. Reintroducir el trauma histórico, dándole un espacio narrativo al asesinato de decenas de miles de civiles, implica una participación activa de la audiencia. Para encontrar una voz, el narrador se inserta en la mecánica de las casas editoriales: “¿Por qué un reportaje sobre Guzmán? Porque vende. O porque yo creo que vende. O porque es lo único que puedo vender. Necesito algo novedoso, y el tema de actualidad del último año, tras el 11-M, es el terrorismo" (Roncagliolo, 2007: 23). 
La intersección de estética y política no es inusual en el mercado editorial latinoamericano. Observamos el encuentro de arte y violencia, por ejemplo, en la literatura de Azuela, García Márquez, Poniatowska, Vargas Llosa y Bolaño. Notamos una trayectoria previa de bandidos, revolucionarios y narcotraficantes identificados como objeto de consumo en mercados locales y trasnacionales. Se compran camisetas del Che Guevara, rimas de José Martí, documentales del subcomandante Marcos y narcocorridos del traficante de moda en Miami, Madrid o Cuidad de México. En nuestro mundo globalizado,

Se habla hoy de la narrativa y el cine de la violencia contemporánea, una nueva configuración que supone una serie de corrimientos del papel del estado con centro gravitacional del conflicto social y como escenario en la consumación de una justicia por venir, un escenario donde el mercado se postula como la racionalidad última (Rosemberg, 2009: 91).

La novela de Santiago Roncagliolo negocia con la categorías epistémicas que fundan la labor periodística en el siglo XXI. El mercado, como racionalidad última, determina los puntos de encuentro tanto de la nota periodística como al arte literario. De manera Bajtineana, La cuarta espada canibaliza una variedad de fuentes para generar una visión caleidoscópica de los protagonistas de un movimiento revolucionario. El texto se divide en tres secciones y un epílogo: la primera se titula "La escuela del terror" y corresponde al trabajo de revelar fuentes y establecer la posición del narrador. La segunda, "La guerra", narra la evolución de Abimael Guzmán, Sendero Luminoso y los comandos contra-insurgentes de la policía y las fuerzas armadas. La tercera parte y el epílogo, bajo el rótulo "La cárcel", se enfocan en la comisión de la verdad, abogados, encarceladas y el punto de vista narrativo.

La cuarta espada entreteje múltiples fuentes desde la cultura pop al comentario editorial, la historia oral y la entrevista de guerrilleros, civiles y militares. Simulando la labor de las comisiones de la verdad instauradas para revelar el enigma de la violencia guerrillera, el collage informativo se asemeja al documental. 
Secuenciando imágenes, documentos, testimonios e incluso rumores, el narrador dedica el volumen: "A todos los personajes de este libro por prestarme su voz. A los 69.208 muertos y a las que aún quedamos vivos" (Roncagliolo, 2007: 1). La aproximación detectivesca a un crimen de 69 mil habitantes implica una observación participativa que se asemeja al texto antropológico. Haciendo eco de etnógrafos peruanos previos como José María Arguedas (1911-1969), el narrador, imaginado desde la posición del autor, hace hincapié en figurar su perspectiva testimonial: "Me llamo Santiago porque mis padres se enamoraron en la capital de Chile, en alguna marcha política, cuando gobernaba Allende" (Roncagliolo, 2007: 73).

En medio de este complejo entramado trasnacional, desnudando su posicionamiento intelectual, el narrador simula un ideal comunicativo imparcial. El viaje del narrador en busca de fuentes se remonta a su infancia. Es hijo de una familia de izquierda que exiliada en México intenta dar razón de la famosa imagen de perros colgados desde el alumbrado en Lima, con el cartel "Deng Xiao Ping: hijo de perra" (Roncagliolo, 2007: 21). La dimensión histórica de la novela parcialmente integra a los familiares de Abimael Guzmán. Los vasos comunicantes incluyen la novela En mi noche sin fortuna de Gladys Guzmán, quien es hermana del líder guerrillero. El narrador comenta, "Hasta la página 136 no encuentro nada que me sirva para mi investigación" (Roncagliolo, 2007: 29). Cuando aparece el personaje Antonia, nota el narrador, "el recurso de la empleada doméstica es una manera de librar su historia de opiniones personales" (Roncagliolo, 2007: 29). El juego de máscaras evoca la adolescencia e interioridad familiar de Guzmán. Con múltiples instancias de espejos narrativos, el narrador introduce a la angélica Clara y el cerebral Luis para desenmascarar al cerebro de la revolución.

Para haber militado en una facción revolucionaria llamada Bandera Roja, Clara me parece una señora muy dulce...Hasta ahora, la única descripción personal que he conseguido del Guzmán académico aparece concedida por otro profesor de esa época, Luis Lumbreras: Abimael era una persona muy afectiva 
y con gran sensibilidad. Nunca he visto tratar con tanto respeto, con tanto decoro, a un pordiosero, a un mendigo, como lo hacía él (Roncagliolo, 2009: 54).

Humanizar al líder guerrillero introduce una lectura del desplazamiento, desde el mito revolucionario a la fragilidad de la vida cotidiana. Reflexionando sobre Abril Rojo (2006), novela anterior que le otorga a Roncagliolo el prestigioso premio Alfaguara del 2006, Lorena Cuya Gavilano nota que la ciudadanía cultural y narrativa representan las complejidades de las narrativas de desplazamiento (2016: 5). El hecho que Abril Rojo, "represente migración como un tema nacional le permite al autor forjar un nacionalismo a larga distancia" (Cuya Gavilano, 2016: 9). De manera análoga a La cuarta espada, Abril Rojo "mantiene las convenciones del thriller de asesino serial" (Prendes, 2010: 229). El detective Feliz Chacaltana "busca escudarse ante la muerte, el dolor y la injusticia al igual que otros se refugian en la comodidad del hogar, en la locura, en el asesinato o la negación de la insoslayable realidad” (Prendes, 2010: 235). La alusión en Abril Rojo al "Sueño del pongo" (1964) de José María Arguedas constata un desplazamiento religioso de la narrativa. Los hilos que entrelazan al autor y su patria regeneran elementos divinos y seculares, "La religiosidad aparece impregnada de marxismo tal y como es frecuente en las ideas de Mariátegui y Sorel" (Veres, 2012: 554). ¿Cómo entonces narrar un trauma histórico, como objeto de consumo, y simultáneamente revelar la racionalidad de un grupo militante?

Las estrategias mediatizadas que forja Roncagliolo para concebir La cuarta espada dan razón de un posicionamiento intelectual que anheló transitar el sendero luminoso propuesto por el socialista indoamericano José Carlos Mariátegui. En la década de los veinte, Mariátegui meditó sobre la Revolución Mexicana, la caída de Imperios Europeos y la crisis China de 1927. En 1923, él acertadamente predijo que la burguesía europea conduciría "a la humanidad a una guerra más cruenta todavía" (Mariátegui, 1994: 348). Fundador del partido Socialista Peruano y editor de la revista avant-garde Amauta, Mariátegui concibió horizontes 
epistemológicos asentados sobre historias locales en consideración de procesos globales. El aparato interpretativo de Mariátegui, comentado a través de la lectura de textos de Vilfredo Pareto y Georges Sorel que poseía en su biblioteca y que citó extensamente en ensayos políticos, emergió entre residuos y mitos que se remiten a aspectos ilógicos e irracionales que fundan procesos sociales. En su trabajo editorial y político, política y estética se intersectan en la preparación de una epistemología futura que emerge de la tensión entre historias locales y una herencia intelectual europea. El objetivo era generar un potencial emancipador.

Para generar el suspenso narrativo, La cuarta espada posiciona información para consumo masivo con la prometedora ilusión de revelar la críptica racionalidad de Sendero Luminoso, ejemplificada con los perros colgados desde el alumbrado limeño. Sendero Luminoso, explorado por las ciencias sociales y el periodista Gustavo Gorriti la década anterior, proclamaba que una revolución sustentada con sangre era históricamente determinada. De manera contra-intuitiva, Sendero Luminoso preparaba a sus soldados para sacrificarse por los ideales de la revolución. Maoístas, como catedráticos de materialismo histórico, aseguraban que la transformación histórica era inevitable cuando una población estuviera dispuesta a ofrecer su vida por una utopía. Aunque, desde fuera, la perspectiva pareciera una demencia, el razonamiento es análogo a las guerras de independencia. En guerras de emancipación, en América Latina o Europa, poblaciones habían sacrificado sus vidas en el nombre de Dios, libertad o amor por la patria. Se presupone el sacrificio de una población local para derrotar a un invasor técnica o militarmente más avanzado.

En 1980, las condiciones sociopolíticas no eran favorables para una revolución. Perú había pasado de una dictadura a una coalición democrática de izquierda y líderes senderistas se opusieron a los planes armados del partido. Abimael Guzmán perseveró, acusando a sus contrincantes de revisionistas, e inició la violencia (Degregori, 2012: 82). La decisión implicó que Sendero Luminoso, una pequeña y desconocida facción de izquierda engendrada en los miles de debates en el sistema educativo de Ayacucho, modificó su estructura para liderar una subversión (Gorriti, 1991: 233). 
En "Pensamiento Militar del Partido" (1980), Guzmán explica que la ideología supedita el conocimiento táctico, "Para hacer guerra, uno debe ser filósofo" (Gorriti, 1991: 184). El comienzo de la insurrección no reflejó un levantamiento armado convencional, en parte porque Sendero Luminoso no tenía armamento. La tensión entre el comandante político, Guzmán, y el comandante militar, Feliciano, se viviría hasta los últimos días de la violencia.

En Perú, la mayoría de los muertos fueron víctima del fuego cruzado entre el estado insurgente y el oficial. Comenta el narrador de La cuarta espada, "Para el analista Raúl González, «las fuerzas armadas no se ganaron a las campesinos. Pero Sendero los perdió. Eran tan salvajes que les retiraron su apoyo»" (Roncagliolo, 2007: 122). La multitud de perspectivas, vía una afirmación o negación del cuerpo de las víctimas, incluye "la narrativa trasnacional de los derechos humanos que está cargada de una historia de protección del individuo contra un estado perpetrador" (Rosemberg, 2009: 96). La cuarta espada enfatiza la responsabilidad compartida por los agentes de la violencia. En Perú, "Si los terroristas desfilaron los cuerpos ensangrentados de sus víctimas para engendrar temor en las comunidades que atacaron, las fuerzas del gobierno peruano enterraron los cuerpos en un intento de encubrir la evidencia de su abuso" (mi traducción de Celis, 2015: 322).

Si recordamos que la visión de Occidente como patrón de la modernidad entró en crisis luego de la Primera Guerra Mundial (1914-18), la labor de Mariátegui correspondió, en nomenclatura decolonial, a desarrollar un sistema epistémico para reconstituir el espacio peruano en un contexto global (Mignolo, 2011: 46). El autor, quien se transformaría en una figura mítica de la izquierda militante, anheló generar una conciencia revolucionaria sin con ello reproducir el autoritarismo residual heredado desde la colonia. El juego de estética y política en Mariátegui, en su trabajo editorial y político, emerge de la tensión entre historias locales y una herencia intelectual europea. Producir una trazo histórico alternativo, desde una perspectiva urbana que hereda la tradición intelectual europea, implicó negociar con categorías epistémicas que produjeron al individuo como agente histórico. Mariátegui, 
como figura intelectual, no escapó su propia mitificación o demonización por revolucionarios e intelectuales.

En Roncagliolo se aprecia un proceso similar, en el cual el narrador se apropia de un proceso histórico, fundado en la muerte y tortura de miles de compatriotas, para generar una estética de consumo masivo. La novela intersecta múltiples dimensiones espaciales, ya sean locales, nacionales y trasnacionales, para revelar una serie de oposiciones que convergen en un proceso histórico traumático.

La tensión entre región y centro, el individuo contra el estado, y la memoria frente a la historia oficial, en una serie de oposición es con las que se ha articulado la literatura (de Rulfo, en Fuentes o García Márquez), los muertos conviven con los vivos en una proposición que coloca a la literatura como mediación y simbólica conciliación entre versiones desencontradas de la historia, o de redención de historias negadas (Rosemberg, 2009: 108-109).

Lo que promete La cuarta espada, un proceso detectivesco liderado por el héroe periodístico, es información reciclada desde la década anterior. La novela intercala la racionalidad de Sendero Luminoso, la labor de las comisiones de derechos humanos latinoamericanos y el reconocimiento de un producto cultural que da cuenta de un trauma histórico reciente. Desafortunadamente, el juego estético mediado por el mercado del siglo veintiuno ha perdido el efecto deseado por Mariátegui, que era generar una cultura política alternativa.

\section{Bibliografía}

Arguedas, J.M. (1974). "El sueño del pongo", En Agua y otros cuentos, 161-168. Lima: Ed. Milla Batres.

Bakhtin, M.M. (1981). The Dialogic Imagination. Austin: University of Texas Press.

Celis-Castillo, P. (2015). “Loss, Emotions, and Politics: Mass Graves, Malancholia, and Performance in Santiago Roncagliolo's 
Abril rojo", Revista Canadiense de Estudios Hispánicos, 39/2, 321-339.

Cuya Gavilano, L. (2016). "Internal Migration, the Publishing Industry, and Transnational Identities in Two Peruvian Writers". Revista Hispánica Moderna, 69, 1, 1-16.

Degregori, C.I. (2012). How Difficult is it to be God? Shining Path's Politics of War in Peru, 1980-1999. Madison: University of Wisconsin Press.

Gorriti, G. (1999). The Shining Path. Chapel Hill: The University of North Carolina Press.

Mariátegui, J.C. (1994). Mariátegui Total. Lima-Perú: Empresa Editora Amauta.

Mignolo, W. (2011). The Darker Side of Modernity: Global Futures, Decolonial Options. Durham; London: Duke University Press.

Prendes Guardiola, M. (2010). "Constantes Temáticas en tres novelas peruanas sobre la época del terrorismo". Romance Notes, 50/2, 229-239.

Roncagliolo, S. (2007). La cuarta espada: La historia de Abimael Guzmán y Sendero Luminoso. Buenos Aires: Editorial Debate.

Rosemberg, Fernando (2009). "Derechos Humanos, Comisiones de la verdad, y nuevas ficciones globales". Revista de Crítica Literaria Latinoamericana, 35/69, 91-114.

Veres, Luis (2012). "Los mitos prehispánicos en la obra de Santiago Roncagliolo”. Bulletin of Hispanic Studies, 89/5, 551-560. 